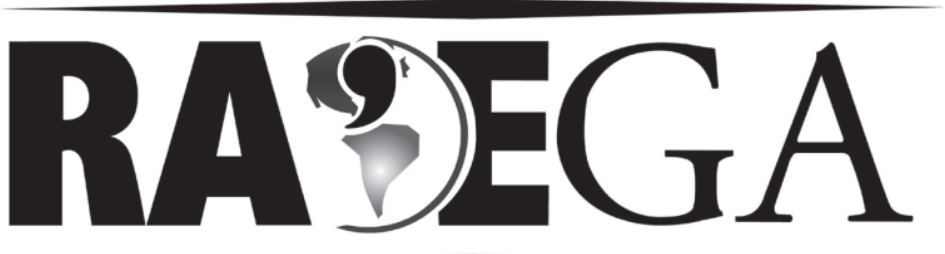

O ESPAÇO GEOGRÁFICO EM ANÁLISE

\title{
CONTRIBUIÇÕES PARA RESSIGNIFICAÇÃO DA PRÁTICA DA EDUCAÇÃO AMBIENTAL PELOS PROFESSORES DE GEOGRAFIA
}

\section{CONTRIBUTIONS TO REFRAME THE PRACTICE OF ENVIRONMENTAL EDUCATION FOR TEACHERS OF GEOGRAPHY}

\author{
Patrícia Mendes Calixto ${ }^{1}$ \\ Arion de Castro Kurtz dos Santos ${ }^{2}$
}

\section{RESUMO}

O texto apresenta considerações sobre um espaço de reflexão durante um processo de formação continuada realizado com educadores do município de Piratini, interior do Rio Grande do Sul. Analisa-se a importância de identificar o conceito de ambiente dos educadores responsáveis pelo ensino de Geografia do município, abrindo assim possibilidades de repensar na prática a inserção da Educação Ambiental a partir de uma mudança paradigmática.

Palavras-Chave: formação continuada, ensino de geografia, educação ambiental.

\footnotetext{
${ }^{1}$ Geografia - Universidade Federal do Rio Grande. Doutorado em Educação Ambiental na Universidade Federal do Rio Grande (FURG). Professora no Instituto Federal Sul-Riograndense. Rua General Balbão, 81 - Bairro Centro. CEP 96.745-000 -- Charqueadas/RS. patriciacalixto@charqueadas.ifsul.edu.br

2 Física - Universidade Federal do Rio Grande do Sul. Doutorado em Science Education University of London, Inglaterra. Professor Titular Instituto de Matemática, Estatística e Física e do Programa de PósGraduação em Educação Ambiental, Universidade Federal do Rio Grande, Campus Carreiros: Av. Itália km 8 Bairro Carreiros. CEP: 96203-900 Rio Grande/RS.
} 


\section{ABSTRACT}

The text presents considerations on a reflection space for a process of continued formation accomplished with municipal district educators of Piratini, countryside of the Rio Grande do Sul state in Brazil. It analyzes the importance of identifying the environment concept of the educators responsible for the municipal district Geography teaching, opening thus possibilities to rethink in the practice the insertion of the Environmental Education starting from a change of paradigm.

Keywords: Continued formation; geography teaching; environmental education.

\section{APRESENTANDO A EXPERIÊNCIA}

O artigo a seguir apresenta o resultado de uma experiência de formação continuada para professores de Geografia em serviço. O objetivo do trabalho foi discutir o conceito de ambiente no âmbito das atividades educativas exercidas pelo grupo, o qual era formado por educadores do ensino fundamental do município de Piratini-RS.

As atividades foram organizadas em encontros quinzenais nos quais possibilitou-se leituras, debates e produção textual. Para conhecer o perfil do grupo participante, realizou-se entrevistas e aplicou-se um questionário. Por fim, realizou-se uma saída de campo para praticar a metodologia de Estudo do Meio, proposta por PONTUSCHKA et al ( 2007), a qual possibilita identificar as peculiaridades do meio vivido e analisar sua complexidade.

A experiência apresentou resultados significativos como o de reforçar a importância da formação continuada como espaço para aprofundar conhecimentos, conhecer novas técnicas de trabalho e ainda promover o intercâmbio com colegas de diferentes escolas. Além disso, um fator relevante é o do educador ter tempo-espaço para refletir sobre sua própria prática, analisando suas dificuldades e principalmente, compreendendo o potencial de seu meio como campo fecundo de produção de conhecimento.

A seguir, é apresentada uma reflexão sobre os principais conceitos que permearam essa experiência, como o de Educação Ambiental, Ensino de Geografia e Formação Continuada. Também há uma descrição das principais etapas que constituíram esse trabalho bem como os principais resultados. 


\section{A INSERÇÃO DO CONCEITO DE AMBIENTE NA CONTEMPORANEIDADE}

É difícil mensurar a quantidade de trabalhos produzidos na última década sobre os mais distintos temas que permeiam a questão ambiental, no Brasil e no mundo. São artigos em revistas especializadas, em Anais de congressos das mais distintas áreas, blogs, jornais, além de livros e produções científicas como monografias de conclusão de curso de graduação e pósgraduação (especialização, mestrados e doutorados).

São também variadas as instituições que direcionam suas atividades político pedagógicas, comerciais e até discursivas para a temática ambiental. Dentre estas estão as escolas, as universidades, as instituições de pesquisa científica, as organizações não governamentais, e, as indústrias de vários setores. Porém, a questão que aflora deste panorama é: qual conceito de ambiente que estas entidades têm? Esta é uma questão importante, pois ela vai mostrar o direcionamento teórico-metodológico adotado nos trabalhos realizados pelos grupos citados anteriormente.

A definição de ambiente, do ponto de vista da Geografia, faz parte do seu repertório de discussões desde a sua constituição enquanto ciência. Basicamente a construção deste conceito deu-se a partir da definição do objeto da Geografia como sendo o espaço geográfico. Consequentemente, a compreensão do que vem a ser ambiente organizou-se em torno da relação do ser humano com o meio. Suertegaray, (2009, p.116), diz que essa relação homem $x$ meio pode ser compreendida de muitas maneiras e cita as formas clássicas:

[...] determinismo geográfico (onde a natureza é a causa); o possibilismo geográfico (onde o mundo humano constrói possibilidades técnicas de utilização da natureza); a interação dialética (onde o ambiental é resultado da relação contraditória entre natureza e sociedade mediada pelo trabalho), a compreensão fenomenológica/hermenêutica (onde não há separação entre ser e ambiente).

Analisando muitas das referências no que se refere a questão ambiental, 
veremos predominância, nos textos de geógrafos, de uma análise crítica do ponto de vista dialético, isto é, o reflexo das consequência das atividades humanas sobre o ambiente natural. Sendo assim, ao adotarmos esta abordagem, estamos assumindo a leitura do mundo como constituído por duas entidades distintas, isto é, o ser humano e a natureza. Esta, no entanto, é uma referência muito forte nos trabalhos do respeitado geógrafo Milton Santos (2006; 2008).

Por outro lado, temos visto frequentes referências nos últimos anos, sobre a compreensão do mundo sob o ponto de vista fenomenológicohermenêutico, especialmente nos trabalhos de Suertegaray $(2001,2009)$ e Rego, Moll, Aigner (2006). Essas leituras tem contribuído para o entendimento da relação entre o ser humano e a natureza, unidos e, em permanente simbiose.

O caminho teórico escolhido, portanto, não é aleatório, pois envolve não apenas questões conceituais, mas também as de ordem política, ideológica e, aquelas relativas à percepção individual e coletiva que temos sobre o conceito de ambiente.

Leff $(2009$, p.11) sinaliza a necessidade da construção de um conceito de ambiente para o que ele chamou de "uma nova racionalidade social, refletida no campo da produção e do conhecimento, da política e das práticas educativas". Portanto, vê-se que a atual conjuntura precisa ser analisada, problematizada e transformada, para a possibilidade de um novo paradigma.

Historicamente, nossa relação com a natureza foi alterada e ao que indica Carvalho (1991), esta ocorre conforme os objetivos e valores de cada grupo social. Para ele, durante a existência das sociedades primitivas, por exemplo, a natureza sequer era distinguida, pois, confundia-se com o espaço vivido desses grupos.

Nos períodos subsequentes, intercalou-se ações de repúdio e adoração a natureza. Estas tensões que cercam a relação ser humano e natureza fazem parte da experiência humana e, por isso, sua compreensão é válida para aqueles que buscam a contextualização da temática ambiental.

Carvalho (2008) aponta períodos diferentes para os momentos de 
tensão e convergência do ser humano para com a natureza. Em um primeiro momento esta relação caracterizou-se pela percepção de uma natureza selvagem e ameaçadora, em outro, como bela e boa.

\section{A MUDANÇA PARADIGMÁTICA NECESSÁRIA}

Os acontecimentos da atualidade, seja no campo da ciência, das artes, da política e também na economia, influenciam fortemente o modo como os sujeitos organizam-se e relacionam-se com o ambiente em que estão situados. E quando pensamos nas inúmeras ramificações, entrelaçamentos decorrentes desta relação, inferimos logo ao conceito de complexidade. Conceito este bastante difundido no meio acadêmico, especialmente através das obras de Morin $(1977,2007)$.

Este autor discute a necessidade de a sociedade reformular sua visão de mundo para a mais abrangente e, assim, consigamos articular os múltiplos saberes. Esta nova visão, de certo modo, já sugere transformação no âmbito educacional, e, diga-se de passagem, que esta seja realizada de fato e não apenas permeie os discursos acadêmicos tanto dos gestores, educadores como dos demais profissionais da educação. Esta mudança passa especialmente, pelo fato de tirarmos o foco no conteúdo e passarmos a olharmos para o desenvolvimento dos processos de aprendizagem.

Outro aspecto, bastante relevante, especialmente para o plano educativo, refere-se à necessidade de não nos fixarmos na aparente simplicidade das coisas. Tentar tornar tudo menos complexo, como frequentemente fazem alguns educadores, pode empobrecer a construção de uma visão ampla do mundo vivido. Assim, o olhar para o meio, como se propõe neste trabalho, não significa simplificar, nem reduzir o que está nele impresso, mas desvelar as raízes daquilo que se apresenta ali.

Essa prática, no entanto, é bastante comum, como demonstra Silva (2005) em sua pesquisa com educadores do ensino básico. Partindo do conteúdo como centralizador do processo de aprendizagem, os docentes tentam minimizar as problemáticas apresentadas pelos temas, e ainda fazem 
um esforço no sentido de reduzir as dificuldades apresentadas pelos seus discentes com relação ao pensamento lógico. Desta forma, o educador elimina a possibilidade de ação de seus educandos, como aponta o autor.

Para Morin (1977) esta simplificação traz mais cegueira do que elucidação. Isto significa reduzir todo o conhecimento a pequenas instâncias e palavras chaves, ocultando facetas que compõem a realidade. Pois, o mundo como sabemos, não é feito de coisas simples, ao contrário, o conjunto de ações realizadas e os propósitos são bastante difusos, assim estar atento a lógica que percorre as escolhas e os rumos, é importante.

O pesquisador Bauman (2001), inclusive, traz a metáfora da fluidez, para caracterizar o tempo atual, em que tudo, especialmente o tempo e o espaço, estão constantemente em processo de mudança. Por isso, afirma este o autor, o mundo deixa de ser previsível. Temos nesse sentido, o questionamento sobre coisas que, tempos antes, não ousaríamos interpelar, como a religião, a família, a escola, a política e as regras sociais, de modo geral.

A questão ambiental, neste panorama, torna-se, portanto, um tema, também complexo, onde não cabem um discurso e uma ação, simplificadores. Pensar no que é ambiente, qual ideologia transita pelo discurso ambiental, bem como, que saberes são produzidos nesta temática, são questões emergentes nesta reflexão, pois tudo isto influencia e é influenciado pelas características apresentadas pela contemporaneidade.

Acrescenta-se a isso, fatores como os apresentados por Leff (2002), que incluem as relações de poder e as formas dominantes de conhecimento como definitivas no entendimento da complexidade ambiental. E esta questão, bem como a apreensão do conceito de ambiente passa pela lógica da ciência.

Aliás, sobre a questão da ciência, Souza Santos (2007) fala em emergência de um novo paradigma, para o qual ele identifica duas dimensões principais: a epistemológica e a dimensão social. A transição epistemológica confere mudanças de um paradigma da ciência moderna para o que ele denominou emergente. No âmbito social, passaríamos de um paradigma patriarcal para aquele em que predomina o poder social, possível contribuinte para uma emancipação social. 
Para tanto, uma transição é necessária, cujo processo se dá em longo prazo:

A transição paradigmática é um objetivo de muito longo prazo. Acontece que as lutas sociais, políticas e culturais, para serem credíveis e eficazes, têm de ser travadas a curto prazo, no prazo de cada uma das gerações com capacidade e vontade para as travar. Por esta razão, as lutas paradigmáticas tendem a ser travadas, em cada geração, como se fossem subparadigmáticas, ou seja, como se ainda se admitisse, por hipótese, que o paradigma dominante pudesse dar resposta adequada aos problemas para que eles chamam a atenção. (SOUZA SANTOS, 2007, p.19).

A análise do autor leva-nos a entender a necessidade de promovermos a mudança imediatamente, para que tenhamos resultados no futuro. Talvez, o surgimento do debate sobre as questões ambientais seja um caminho para esta mudança, embora muitas vezes esse esteja apoiado em preceitos que dificilmente contribuirão para a efetiva transformação. Um dos exemplos mais recorrentes com relação a isso, vê-se nas campanhas que visam a reciclagem, sem que se leve a refletir sobre a outra ponta do processo que é o consumo. Mas isto faz parte de uma sociedade repleta de contradições, na qual, nem sempre os problemas são atacados na sua totalidade.

O fato é que ainda não há resposta objetiva sobre qual o modo mais adequado de construir uma sociedade equilibrada. Porém, alguns modos de vida alternativa foram abordados por alguns pesquisadores. Velasco (2003, 2008) propõe o ecomunitarismo, como educação problematizadora, a qual se baseia nas normas da ética argumentativa como uma nova organização socioambiental, pós-capitalista, em que os homens, através de sua prática efetiva, teriam como base a solidariedade. Nesta organização, as comunidades se integram em redes, partindo do local até atingir todo o planeta. Esta estrutura estaria permeada pela articulação de serviços mútuos que seriam trocados solidariamente de forma gratuita.

\section{A IMPORTÂNCIA DA FORMAÇÃO CONTINUADA}

O atual contexto social, ao longo dos últimos tempos, criou uma série de 
demandas à escola e, evidentemente ao educador, que tornam a formação continuada para professores em serviço, uma necessidade (RAMALHO, NUÑES e GAUTHIER, 2003).

E, sob este espaço da formação torna-se possível abordar perspectivas de âmbito ambiental que poderão ser traduzidas em um novo paradigma para a introdução desta referência temática na escola.

Então a responsabilidade de um educador em ultrapassar as barreiras das aparências é grande, pois ele pode mediar, durante o processo de aprendizagem, o entendimento dos seus estudantes acerca do espaço local. Questionando, orientando os caminhos, avaliando as alterações no espaço geográfico e, assim, ampliar o campo de visão que ele tem sobre determinadas situações.

Neste contexto, a proposição de atividades que orientem os participantes da formação a repensar as problemáticas que emergem em seu espaço de ação, podem contribuir com a reflexão sobre questões de ordem teórica e prática, no que se refere ao tema ambiental.

Buscando contribuir com um grupo de educadores do ensino básico, desenvolveu-se um projeto de formação continuada do município de Piratini, interior do Rio Grande do Sul. O objetivo da criação deste espaço-tempo foi proporcionar momentos de integração, reflexão e debate entre professores de Geografia sobre a questão ambiental local. Atividades variadas foram aplicadas, como leitura e debate, produção de textos, questionários, entrevistas e finalizamos com uma saída de campo.

O foco foi apresentar a importância dos estudos locais, especialmente a partir da Geografia Escolar, como um fecundo espaço para análise e problematização da realidade onde nossos educandos estão inseridos. Através da metodologia do estudo do meio, como aponta Pontuschka et al (2007) é possível proporcionar aos nossos educandos o uso de todos os sentidos para conhecerem melhor um lugar, também os conduz a ter um outro olhar sobre este lugar.

Durante a formação continuada, analisou-se que a introdução de atividades como a leitura e, posteriormente o registro escrito das ideias que se 
apresentaram, trouxe um série de resultados positivos, como por exemplo, o questionamento do plano de ensino em vigor e o planejamento de novas ações pedagógicas.

A formação continuada é sem dúvida uma grande contribuição já que em um momento como o atual, no qual há exigência para um educador reflexivo, participativo e que, sobretudo, questione a realidade em que está inserido como aponta Castro (2005).

Muitas vezes a rotina impede que sejamos sensíveis à beleza, às contradições e até às oportunidades oferecidas pelo meio em que estamos inseridos. Assim, a escola, através do ensino de Geografia, pode possibilitar a ampliação da visão de mundo, bem como favorecer a oportunidade de se perceber as muitas conexões que os lugares distintos mantém entre si. Podemos, assim podemos educar para o respeito, especialmente a partir de uma visão sistêmica do ambiente em questão, no qual, nós, sujeitos atuantes, estamos totalmente integrados.

Esta experiência mostrou a importância de que as políticas de gestão escolar permitam que seus educadores tenham tempo para ler, pesquisar, participarem de eventos na área de educação para que estejam sempre atualizados. A promoção de encontros locais entre os professores pode ser uma boa opção para que se possa fazer intercâmbio de ideias, experiências e especialmente de atualização. Além é claro, de oferecer bibliotecas atualizadas e equipamentos para a inserção das tecnologias na prática pedagógica.

\section{ELEMENTOS SIGNIFICATIVOS PARA ENTENDER A PRÁTICA}

Durante o período de formação continuada em Piratini-RS que estendeuse por 18 meses, aproximadamente, fizemos o levantamento de dados que pudessem nos revelar como se dá a prática desses educadores naquele contexto, no que diz respeito a temática ambiental, dentro do campo de ação da geografia Escolar. Para isso, começamos definindo perfil do grupo.

São 14 sujeitos no total, sendo 12 mulheres e 02 homens; 01 está na faixa dos 30 anos, 08 do total estão na faixa dos 40 anos, 04 na faixa dos 50 e 
um nos 60 anos. Todos trabalham com o ensino fundamental.

Doze educadores possuem o ensino superior, enquanto dois deles têm o ensino médio (magistério). Com relação a licenciatura em Geografia, apenas 03 a fizeram, embora, todos lecionem a disciplina. São pós-graduados 07 dos 14 educadores, mas nenhum em Geografia.

Este perfil pode justificar alguns dos dados levantados pela pesquisa, como por exemplo, a dificuldade em abordar a cartografia escolar. Supomos que isto esteja relacionado a formação inicial, a qual influencia o domínio de alguns termos conceituais em detrimento a outros. Conforme Machado (1994), embora a formação universitária não influencie fortemente as atitudes em relação ao ambiente, cursos como Geografia e Biologia, historicamente, discutem a dinâmica conceitual relacionada ao tema ambiental. No grupo há alguns graduados em História e Ciências Sociais. Além disso, metade do grupo é pós-graduada, entretanto, nenhum dos cursos está relacionado a Geografia, mas a administração ou supervisão escolar.

Além do fator acima relatado, um outro relevante é de que seja provável o predomínio de aulas tradicionais, pois segundo Vesentini (2004), este perfil de educadores, isto é, com formação diferente da Geografia, não discutiu a renovação da Geografia a partir da década de 1980. É possível, assim, que a Geografia seja entendida como uma reprodução de saberes enciclopédicos exigindo apenas memorização, contrariando a abordagem da aprendizagem significativa de Ausubel (MOREIRA, 1999).

Em relação aos questionamentos sobre a questão ambiental temos a seguinte situação: parte dos educadores apresentou dificuldade em dizer o que é ambiente, por isso, houve solicitação do grupo para que pudessem responder em conjunto. Esta situação não foi permitida, uma vez que importava à pesquisa, o que cada sujeito pensa sobre a questão ambiental.

Após o cumprimento da atividade verificou-se esta condição: com exceção de uma das educadoras, todos os demais disseram que ambiente é o MEIO, também houve aproximação do conceito de ambiente com a palavra TUDO. Esses conceitos demonstram a dificuldade desses sujeitos em identificar elementos componentes do ambiente. Ao dizerem que é meio ou é 
tudo, simplificam algo complexo, ou seja, demonstram uma perspectiva limitada da questão. Algumas pesquisas avaliam esta situação em outros grupos, como a de Shepardson (2005), que avaliou em um grupo de estudantes suas concepções de ambiente e revelou que estas: “... (a) são baseadas nas suas observações, interações sociais e linguagem; (b) são semelhantes na mesma idade, habilidades, gênero e cultura; (c ) não são facilmente mudadas; e (d) sofrem influência da aprendizagem científica em caminhos não convencionais". Há, portanto, um grande desafio em contribuir com interações significativas, as quais representem uma possibilidade de ter acesso a outras concepções sobre este tema. A formação continuada, neste caso, pode ser um caminho adequado para refletirem sobre o tema e reelaborarem seus conceitos, embora haja indícios de que esta tarefa seja difícil.

$\mathrm{Na}$ mesma questão, sobre o que é ambiente, a relação HOMEMNATUREZA, apareceu em um dos questionários e SER HUMANO em outro. A apresentação deste dado pode evidenciar que, naquele meio/tudo, indicado anteriormente, talvez o homem seja algo a parte, já que apenas dois, dos 14 questionados explicitaram este elemento em seus conceitos. Para Carvalho (2008) esta situação pode estar relacionada a uma visão naturalizada da questão ambiental, em que o homem, quando visto, é oposição a natureza. Portanto, há evidencia de que o grupo considere o ambiente como algo intocável e equilibrado, sem a interferência humana.

Sobre a Educação Ambiental, esta foi apontada como trabalho ou meio de promover a CONSCIENTIZAÇÃO e a PRESERVAÇÃO do meio ambiente. Estes apontamentos, feitos pelos educadores, revelam o modo como essa temática é concebida por este grupo. De forma reduzida, a EA é apontada como aquela que pode mudar um comportamento visando a preservação. $O$ fato de a indicarem como promotora de conscientização reforça a tese de que, apesar de todo debate suscitado no que se refere a $E A$, ainda há uma visão conservadora sobre a sua aplicação. Loureiro (2004, p.27) analisa que este fator é "crônico" no fazer pedagógico, pois a educação ainda é “...impositora de condutas vistas como corretas...".

Em conversa informal, identificou-se que a palavra preservação é 
confundida com conservação e que isto está associado a elementos naturais, como matas, florestas e rios. De fato, esses conceitos não são comumente diferenciados e, com frequência são usados como sinônimos. Pádua (2009) avalia o uso desses termos diferenciando-os da seguinte forma: conservar pode ser usado quando se permite a intervenção humana, inclusive na referência ao uso de recursos naturais. Para a legislação ambiental brasileira, os autores citados, tais como Carvalho (2008), Loureiro (2004) e Pádua (op.cit) apontam que o termo é usado para designar proteção aos recursos naturais, garantindo o uso racional, baseado nos princípios da sustentabilidade. Preservar, é empregado a algo que precisa ser totalmente protegido, tornandoo intocável. Em geral, é usado para espécies, ecossistemas e biomas que correm o risco de perder a biodiversidade.

Verificou-se ainda que, na primeira questão, meio ambiente foi associado a NATUREZA, a PLANETA e a ECOSSISTEMA, esses fatores apontam, mais uma vez, para uma visão naturalista, proveniente de aspectos ligados a paisagem. Em 1994, uma pesquisa coordenada por Machado, apontou a percepção de estudantes universitários em Minas Gerais, onde identificou perspectiva semelhante. Embora este trabalho tenha sido realizado há aproximadamente dezessete anos, nota-se a permanência da visão naturalista, o que não significa pouco trabalho para minimizar esta questão, porém há indicação de que muito ainda há para ser feito.

Também questionou-se a participação do grupo em palestras, cursos e/ou eventos relacionados a EA. Dos 14 sujeitos, 11 já haviam participado. É notório que, embora a maioria tenha participado de atividades relacionadas ao tema meio ambiente, isto não contribuiu para que houvesse uma mudança no paradigma naturalista da questão ambiental. Conceitos e termos são usados de modo a fortalecer a oposição na relação homem-natureza.

Esses dados parciais revelam a necessidade de uma proposta educativa onde a questão teórica seja tão importante quanto a prática da EA. Este modo fragmentado com que olham para seu meio, contribui para um direcionamento pedagógico, onde o tema meio ambiente, está voltado para ações de conscientização, as quais orientam para a preservação de algo que faz parte 
do mundo externo. Esta situação evidenciou-se nas conversas informais, nas quais, tais sujeitos, revelam não conseguir perceber o seu local como fonte de análise para a EA.

Outro ponto relevante é pensar na abordagem da EA, a partir de seus fundamentos, como elemento importante para a transformação social. Não apenas o debate sobre o tema, mas apresentar sua possibilidade de proposta educativa baseada no diálogo, no exercício da cidadania e pontuando a formação do sujeito ético, valorizando o sentimento de pertença.

Conforme sugere a Teoria da Aprendizagem Significativa de Ausubel (MOREIRA, 1999), identificando essas limitações conceituais, é possível planejar novos modos de inserção deste tema, garantindo a incorporação das novas concepções.

Neste caso, a formação continuada é um espaço de fundamental importância para que os educadores tenham acesso a informações atualizadas sobre conceitos, pesquisas e novas práticas, no entanto, precisam ser regulares, bem planejadas e realizadas por especialistas.

\section{A EXPERIÊNCIA: ANALISANDO O CONCEITO DE AMBIENTE DOS EDUCADORES}

A partir da identificação do que pensavam os educadores sobre o tema ambiente, foi possível entender seus posicionamentos durante a leitura e debate sobre textos relacionados à temática. Neste sentido, os encontros foram muito importantes, pois, proporcionaram a esses educadores espaço para que, junto de seus pares, pudessem analisar e avaliar a realidade vivida na escola.

A Educação Ambiental como tema central deve-se ao fato de que este tem sido frequentemente usado por educadores geógrafos, principalmente, para o exercício da conscientização. Então, perguntamo-nos o que é conscientizar? Para quê? E como fazemos isso?

O conceito de conscientização aqui é tomado de Freire (1979) que o identifica como o resultado da apreensão crítica da realidade, onde a desvelamos em sua essência. E, esse desvelamento, implica em ação, isto é, o 
processo de conscientização passa pela práxis, pois é através dela que o homem transforma o mundo.

Durante os encontros procuramos saber como esses educadores compreendem alguns conceitos fundamentais que permeiam a Geografia e a Educação Ambiental. Esses dois saberes caminham na mesma direção, ou seja, problematizam a ação humana sobre um espaço físico e o resultado disso sobre a sociedade. Neste sentido, o ensino de Geografia pode contribuir com a apreensão dos conceitos espaciais, para a compreensão das relações que ali se sobrepõem de modo a orientar o sujeito a agir de modo mais ético e responsável.

A EA, por sua vez, atravessa todo discurso geográfico com conceitos como sustentabilidade, percepção ambiental, economia, meio ambiente, conscientização, entre outros. Portanto, esta evidente articulação com a Geografia justifica a iniciativa de orientarmos os educadores, participantes desta formação continuada, desenvolvida em Piratini-RS, a investir em metodologias como a de estudo do meio, com respaldo nas saídas de campo, o que incluirá também o uso de mapas com referências locais. O estudo do meio favorece a leitura do espaço ocupado e a interpretação das transformações empreendidas pela sociedade (Pontuscka et al, 2007).

Entretanto, o problema inicial identificado foi a dificuldade apresentada por esses educadores na formulação do conceito de ambiente. Isto é relevante, pois ao perceber essa situação logo no início houve a possibilidade de reorientação do trabalho planejado. Principalmente, porque inicialmente pensou-se em atividades onde o ponto de partida fosse a análise da complexidade que envolvesse a realidade local. Isto certamente complicaria o entendimento das atividades e textos reflexivos, empobreceria os resultados desejados e, é possível que as práticas escolares não tivessem continuidade posteriormente, como era o desejado.

O que se pautou, portanto, foi a necessidade de buscarmos nos aproximar do mundo vivido dos sujeitos envolvidos pelo trabalho. É isto que dirá que grupo é esse, como ele pensa e qual encaminhamento mais adequado para este grupo. 
O entendimento do conceito de ambiente, permeado por referências bibliográficas adequadas, possibilita a análise e a problematização de situações presentes no cotidiano desses educadores e seus alunos. Para isso, a articulação entre a geografia escolar e a Educação Ambiental precisam ser pautadas em conceitos sólidos e bem trabalhados. Além disso, o debate possibilita o levantamento de questões comuns e adversas no grupo, o que favorece um avanço dos participantes para além das percepções superficiais.

Depois, então, do levantamento dos dados com base em um questionário e nos registros dos conceitos, realizou-se um debate. Por fim, o grupo reescreveu seu conceito de ambiente, o qual permeou todo trabalho subsequente desta pesquisa.

\section{RELEVÂNCIA DA FORMAÇÃO CONTINUADA PARA RESSIGNIFICAÇÃO DA PRÁTICA}

Conforme já dissemos anteriormente, o atual contexto sócio histórico exige a reformulação do paradigma vigente baseado na racionalidade técnica. Disto decorre que a educação passa também por um momento no qual a escola como instituição, seus profissionais, especialmente o educador, os educandos e a sociedade como um todo, questionam seus papéis diante de um mundo em transformação. Percebe-se que há razões bastante fortes para um encaminhamento ao contínuo aprendizado dos educadores. Um desses motivos tem sido o intenso apelo para a mudança paradigmática proposta por Souza Santos $(2006 ; 2007)$, pois segundo o pesquisador é preciso promover a consciência multidimensional, já que toda visão especializada é pobre.

Rodrigues (2008) sugere uma educação voltada para a complexidade que atenda as demandas sociais, contribuindo para a emancipação e autonomia dos sujeitos, em que haja flexibilidade, diálogo e, que possa ser desempenhada acadêmica, cientifica, humana e criativamente. A autora ainda considera necessário: 
[...] renunciar a alguns dos saberes já prontos, em suas certezas e definições, experimentando outros conceitos, categorias e bases curriculares flexíveis, nos quais não se renegue a ciência, o saber e o conhecimento já elaborados a duras penas pela humanidade, mas, certamente, aos quais seja possível dar novos sentidos e significados. (RODRIGUES, 2008, p.98)

No entanto, as mudanças sugeridas requerem transformações que estão além da formação docente, elas perpassam a política, a instituição e também, é claro, a formação inicial deste profissional. Devemos considerar que esta mudança não ocorre da vontade individual, nem de um pequeno coletivo, mas de uma alteração na estrutura política e institucional que ofereça as oportunidades para a efetivação deste processo.

É claro que o educador tem um grande papel a cumprir, e, assim como em outras profissões, pode buscar novos desafios, incorporar as mudanças em suas tarefas cotidianas, porém isto será facilitado se houver uma estrutura que Ihe garanta esta possibilidade. Além disso, a percepção sobre sua profissão pode passar por uma reavaliação, na qual analise que não é favorável esperar, receber e aplicar os dispositivos desenvolvidos em outras esferas. Ele é o agente principal, como dizem os autores citados acima e por isso mesmo, também responsável pelas transformações.

Neste contexto, a formação continuada de professores em exercício é um meio através do qual é possível contribuir para a melhoria de tal situação. Isto porque as competências docentes são tratadas coletivamente e continuamente. O exercício profissional é posto em análise, é avaliado e reorientado, com base nas experiências compartilhadas. Segundo Carvalho (2005, p.97), nos últimos anos a formação continuada tem colocado o professor como centro do processo de pesquisa sobre sua própria prática, "exercendo papel de ator coletivo social na transformação do cotidiano escolar e para além dele".

Pesquisadores como Leitão (2004) apontam que a possibilidade de refletir e teorizar sobre a ação, além de permitir a investigação de metodologias e experiências contribui para a socialização de práticas, as quais vêm sendo empreendidas. Isto significa não apenas lançar um novo olhar para sua prática, 
mas aprofundar questões relevantes, além de motivar o desenvolvimento do processo criativo.

Assim, educadores preparados estarão aptos para apropriarem-se dos saberes os quais são produzidos no cotidiano, de maneira que questões conceituais possam ser aprofundadas e melhor aproveitadas em termos de aprendizagem (NÓVOA, 1995). Por este motivo, há indicadores de que o caminho solitário para a formação é insuficiente, uma vez que a construção coletiva contribui para outros entendimentos sobre a própria prática.

Aliás, este novo processo, no qual o trabalho coletivo se faz necessário, vem ao encontro das exigências sociais, como a questão do mercado de trabalho que exige profissionais cada vez mais habilidosos na prática de trabalhos em grupos, de gerenciar processos e de criticar propostas (CASTRO, 2005). Portanto, educadores preparados para encarar esse novo panorama são, no mínimo, garantia de mais qualidade na prática de ensino. E para isso, é importante estarem atentos a mudança de perspectiva em todo o seu cotidiano de trabalho, seja no relacionamento com os colegas, seja na mudança de direção de seu foco que, ao que tudo indica, precisa sair do conteúdo e passar para a formação do sujeito de modo integral. Entretanto, isto tem sido uma barreira, já que grande parte dos profissionais apresenta formação voltada para a racionalidade técnica.

É neste contexto que vem sendo sugerida a formação reflexiva como um modelo que visa o atendimento da necessidade de um novo perfil de profissional: participativo e autônomo (op. cit.), que abarque a complexidade e a singularidade de seu trabalho. Isto se dará quando este profissional olhar para a sua experiência analiticamente, interpretando-a. Pinto (2008, p.103) recomenda que a formação continuada esteja:

[...] balizada em princípios que provoquem a reflexão sobre a prática e sobre o entorno para além dela e valorizem os professores como protagonistas de sua formação. Essa formação é vista como um processo contínuo e diário constituído durante o desempenho da atividade profissional, de onde resultam os saberes de que os professores são portadores, os quais são mobilizados no exercício da ação docente. 
Com esta nova postura espera-se que os cursos de formação continuada não sejam um fim, mas um começo para o processo de transformação. Isto é, esses espaços devem propiciar aos educadores uma nova postura, onde a mobilização para a produção de novos saberes faz-se presente, e principalmente, que eles acreditem em sua capacidade.

É preciso ressaltar o fato de que este olhar para a sua prática e fazer dela seu enfoque não minimiza a necessidade de busca pelo aporte teórico. Ao contrário, reforça a necessidade de leitura, pesquisa e análise do que tem sido disponibilizado pela academia e seus pesquisadores.

Essas discussões atravessam aquelas discutidas no cerne da EA, pois o ambiente é tratado como um espaço onde a cultura, a economia, a política e a sociedade se articulam através de suas ações cotidianas. Assim, o educador tem em suas mãos a responsabilidade de ampliar o campo de discussão a partir das questões locais, problematizando as alterações ambientais como consequência de atitudes tomadas no campo político e econômico, e não como mero acaso. E, que estas decisões, na maioria das vezes, estão pautadas em um sistema econômico concentrador, hierárquico e cujo poder de decisão está na mão de poucos.

Assim como na EA, a formação continuada não pode ser uma via de mudança comportamental, mas uma possibilidade de se perceber a responsabilidade individual e coletiva sobre esta situação e, sobretudo, visando a autonomia dos sujeitos envolvidos.

Baseando-nos nessas considerações, fizemos desta experiência em Piratini-RS um espaço de contribuição com aqueles educadores, pois observou-se uma precariedade na sua formação. Conceitos ambientais e aqueles referentes ao ensino de Geografia eram carregados de senso comum ou não estavam sendo aplicados em razão de uma deficiência na formação básica, apontada pelo próprio grupo, ao longo dos encontros. Na sequência, obviamente o encaminhamento dos trabalhos foi orientado para mostrar as possibilidades de mudanças na prática, as quais estariam sustentadas pela experiência e pela criatividade dos sujeitos. 
Neste sentido, a formação continuada que se desenvolveu no município citado, teve como orientação o fortalecimento de uma prática que fosse firmada na formação de sujeitos cooperativos, solidários e éticos, como requer a EA. Que respeitem as diferenças, compreendam a contemporaneidade e suas características como algo que não pode ser negado pela equipe docente. $E$ também que tenham o espaço geográfico como alicerce para discussões de ordem, não apenas física, mas também subjetiva, pois nele estão e ficarão marcadas as decisões humanas as quais estão baseadas em valores éticos, morais, políticos, econômicos e culturais.

Também é importante ressalvar que a prática de formação continuada aqui abordada não pretendeu intervir na realidade desses educadores e determinar metas para que estes alcancem resultados imediatos. Entendemos os encontros oferecidos como o princípio de um trabalho que pode ser ampliado por outros pesquisadores. Seja através de outros cursos e palestras, mas também da indicação de caminhos para buscarem suas próprias direções rumo àquilo que eles acreditam ser adequado para suas experiências. Como analisam Pinto, Barreiro e Silveira (2010), a formação continuada não pode ser apontada como um fator determinante para a atuação dos educadores, entretanto, é um espaço para a reflexão sobre sua prática, para atender as necessidades dos seus educandos e para criação de alternativas criativas para suprir tais desafios.

Outra análise importante é trazida por Ramalho, Nuñes, Guathier (2003, p.23), que aqui, embora direcionem sua contribuição para a formação inicial do profissional docente, trazem luz a essa discussão com a seguinte referência:

Assumir a reflexão, a crítica, a pesquisa como atitudes que possibilitam ao professor participar da construção de sua profissão e no desenvolvimento da inovação educativa, norteia a formação de um profissional não apenas para compreender e explicar os processos educativos dos quais participa, como também para contribuir na transformação da realidade educacional no âmbito de seus projetos pessoais e coletivos. (grifo dos autores) 
É relevante notar que essas mesmas atitudes apontadas pelos autores para um professor em formação, não são menos pertinentes para aqueles já em processo de trabalho e, cuja aprendizagem, é contínua. Se nossa intenção é de que esses profissionais sejam capazes de, no âmbito de seu espaço de ação, promover os questionamentos e as exigências necessárias para a efetiva mudança, este processo, é claro, passa pelas atitudes apontadas pelos autores.

Pavan (2011) faz uma reflexão significativa sobre a influencia e a importância de uma formação baseada na reflexão em que esteja em pauta a racionalidade técnica. É preciso, segundo a pesquisadora, avaliar o quão esta perspectiva é limitada, não abrangendo, portanto, todas as tratativas do trabalho docente:

[...] postular a reflexão crítica como imperativo para a formação docente, vendo-a como processo complexo e inacabado, é reconhecer não uma visão reducionista, mercadológica, de que precisamos estar em constante atualização, mas sobretudo reconhecer a dinamicidade da sociedade humana e sua possibilidade de mudança. É ver no trabalho educativo a contribuição para a construção de uma sociedade sensível aos problemas sociais e comprometida com sua resolução. E essa prerrogativa da educação só é possível se professores e professoras tiverem um processo de formação crítica (PAVAN, 103, p. 2011).

Por isso foi fundamental em todas as etapas deste trabalho ouvir esses educadores para que fosse possível uma interação e uma ressignificação do que estava sendo proposto. Conforme aponta Tardif (2008) esta é uma condição importante para não recairmos em análises cuja questão social é vista de "fora" do campo de ação. Se o trabalho docente é social, portanto, entendendo esta relação social como uma tarefa complexa que se dá com o outro, penso que considerar o que eles têm a dizer e o que fazem é fundamental para entender a sua prática e, assim, contribuir com a construção de um novo saber. Assim, espero que as problematizações continuem 
alimentando o debate entre eles e que outros sujeitos sejam acolhidos em novas etapas.

É importante ressaltar a notória reação positiva que o encontro referido anteriormente, durante a formação continuada, trouxe para o grupo já que os levou a questionar e refletir sobre o modo como olham para o seu local. Vários professores destacaram que poderiam direcionar melhor suas atividades se olhassem mais para o lugar onde atuam.

O grupo apontou o quanto é comum, associarem a EA a um processo de conscientizar para questões pontuais, como a separação do lixo e a preservação. Não haviam ainda pensado que a EA é um processo maior, que envolve a formação de sujeitos autônomos, éticos, responsáveis, não só com relação ao ambiente físico, mas também com o social, o cultural e o econômico.

A atividade de escrever e depois analisar sua produção para reescrever, trouxe a eles uma percepção de que um conceito, aparentemente tão popularizado quanto o de ambiente, carrega em si, um significado muito complexo.

\section{CONCLUSÃO}

O referido artigo trouxe reflexões sobre uma experiência de formação continuada com professores de Geografia, do ensino básico. O objetivo foi promover momentos de debate, problematização e análise de práticas e referências relativas a questão ambiental. Além disso, o fato de estarem em contato com outros colegas, durante esses encontros, favoreceu não apenas o intercâmbio de informações, mas, sobretudo, a reflexão sobre a própria prática.

De modo geral, identificamos através da atividade relatada neste artigo que os professores de Geografia de Piratini-RS apresentam dificuldades em trabalhar com as questões ambientais. Dentre estas, está o fato de que há uma simplificação do conceito de ambiente, além de um pensamento fragmentado sobre o mesmo, no qual o homem é visto como um elemento a parte no contexto. A EA é vista como um meio de promoção da conscientização, o que 
reduz, significativamente sua finalidade. A visão predominante do grupo é a naturalista, isto é, a natureza é vista como uma entidade que não pode ser tocada e que o homem, enquanto ser social é destruidor e, essencialmente mal.

É importante ressaltar que os objetivos inicialmente foram atingidos e ainda permitiram planejarmos outras atividades posteriormente, em virtude da aceitação por parte desses professores. Com tudo isso, verificamos que as oportunidades para formação continuada são fundamentais para o amadurecimento de algumas propostas. Também contribui para 0 esclarecimento de muitas dúvidas com relação as temáticas que surgem ao longo das atividades diárias, em sala de aula. Muitas vezes, os professores não têm oportunidade, no seu dia a dia, de discutir e esclarecer problemáticas e, a formação continuada permite que não só haja o processo de reflexão, mas também a promoção de intercâmbio de ideias e de materiais didáticos entre si.

\section{REFERÊNCIAS:}

BAUMAN, Z. Modernidade líquida. Trad. Plínio Dentzien. RJ: Jorge Zahar Ed., 2001.

CARVALHO, I.C Educação Ambiental: a formação do sujeito ecológico. 3ed. São Paulo: Cortez, 2008

CARVALHO, M. O que é natureza.1. ed. Brasiliense.1991. (coleção primeiros passos).

CARVALHO, J. M. O não-lugar dos professores nos entrelugares de formação continuada. Revista Brasileira de Educação. N. 28, 2005.

CASTRO, A. M. D. A. Mudanças tecnológicas e suas implicações na política de formação do professor. Ensaio. Avaliação políticas públicas em Educação. RJ, vol13, n.49, out-dez, 2005. p.469-486.

FREIRE, P. Conscientização. São Paulo: Cortez \& Moraes, 1979.

FREIRE, P. Pedagogia do oprimido. 17 ed. RJ: Paz e Terra, 1987.

Pedagogia da autonomia. 25 ed. São Paulo: Paz e Terra, 1996.

LEFF, E. Epistemologia ambiental. São Paulo: Cortez editora, 2002. 
Saber Ambiental: sustentabilidade, racionalidade, complexidade,

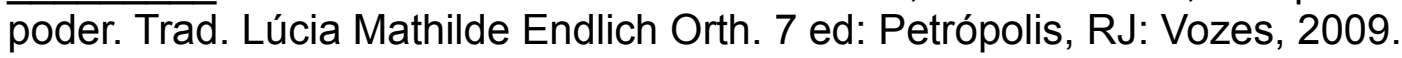

LEITAO, C. F. Buscando caminhos nos processos de formação/autoformação. Revista Brasileira de Educação. N. 27, 2004.

LOUREIRO, F. C Trajetórias e fundamentos da Educação Ambiental. Ed. Cortez, 2004.

MACHADO, Lucy M. C. P. Percepção do meio ambiente por estudantes universitários. Cadernos de geografia. $\mathrm{BH}$, vol. 05, n. 06, dezembro, 1994.

MENDONÇA, F., KOZEL, S. (org). Curitiba: Ed. da UFPR, 2002. Reimp. 2004. 1 ed. ver. 2009.

MEYER, N.J \& Munson, B. H. Personalizing and Empowering Environmental Education Through Expressive Writing. In. The Journal of Environmental Education. Vol.36, n. 03, 2005.

MOREIRA, M. A. A teoria da aprendizagem significativa. Subsídios teóricos para o professor pesquisador no ensino de ciências. Instituto de Física. UFRGS, 2009. Disponível em: <http://www.if.ufrgs.br/ moreira/Subsidios6.pdf> Acesso em: maio de 2011.

MORIN, E. O método: a natureza da natureza. 2 ed. Publicações EuropaAmérica, 1977.

MORIN, E. Introdução ao pensamento complexo. 3 ed. Porto Alegre, Sulinas, 2007.

NÓVOA, A. Formação de professores e formação docente. In: NÓVOA, A. (org.). Os professores e a sua formação. Lisboa: Publicações Dom Quixote, 1995.

PÁDUA, S. Afinal, qual a diferença entre preservação e conservação? [2006] Disponível em: <http://www.oeco.com.br/suzana-padua/18246oeco15564> Acesso em: Maio de 2009.

PAVAN, R. A importância da reflexão crítica para a formação dos professores e professoras. In: Processos e práticas na formação de professores: caminhos possíveis. ZANCHET et al. Brasília: Liber Livro Editora, 2011.

PINTO, C. L.L. Um trem chamado desejo: a formação continuada como apoio a autonomia, a inovação e ao trabalho coletivo de professores do ensino médio. (Tese de doutorado) Universidade do Vale dos Sinos, 2008. 
PINTO, C.L.L., BARREIRO, C.B., SILVEIRA, D.N., Formação continuada de professores: ampliando a compreensão acerca deste conceito. Revista Thema. 07 (01), 2010.

PONTUSCHKA, N. N. ; PAGANELLI, T. I. ; CACETE, N. H. . Para ensinar e aprender Geografia. São Paulo: Cortez Editora, 2007

RAMALHO, B. L. NUÑEZ, I.B., GUATHIER, C. Formar o professor, profissionalizar o ensino: perspectivas e desafios. Porto Alegre: Sulina, 2003.

REGO, N, MOLL, J., AIGNER, C. (orgs). Saberes e práticas na construção de sujeitos e espaços sociais. Porto Alegre: Editora da UFRGS, 2006.

RODRIGUES, Z.A.L. Paradigma da ciência, do saber e do conhecimento e a educação para a complexidade: pressupostos e possibilidades para a formação docente. Revista Educar. N. 32, UFPR, 2008.

SANTOS, M. A Natureza do Espaço: Técnica e Tempo, Razão e Emoção. 4. ed. 2. reimpr. - São Paulo: Editora da Universidade de São Paulo, 2006.

Por uma geografia nova: da crítica da geografia a uma geografia crítica. 6ed. São Paulo: EdUsp, 2008.

SANTOS, B. S. Pela mão de Alice: o social e o político na pós-modernidade. 11 ed., São Paulo: Cortez, 2006.

Para um novo senso comum: a ciência, o direito e a política na transição paradigmática. 6 ed. São Paulo: Cortez, 2007.

SHEPARDSON, D. Student Ideas: What Is an Environment? THE JOURNAL OF ENVIRONMENTAL EDUCATION VOL. 36, N. 4, 2005.

SILVA, V. P. da. Novas tecnologias no ensino de geografia: possibilidades e limites em questão. Rio de Janeiro: UFRJ/PPGG/IGEO, 2005 (Tese de doutorado).

SUERTEGARAY, D. Espaço geográfico uno e múltiplo. In. Revista eletrônica de geografia y ciências sociales. Universidade de Barcelona, 2001.

SUERTEGARAY, D. M. Geografia física (?) geografia ambiental (?) ou geografia e ambiente (?) In: Elementos de epistemologia da geografia contemporânea.

TARDIF, M. Saberes docentes e formação profissional. 9 ed., Petrópolis, RJ: Vozes, 2008. 
VELASCO, S. L. Ética e globalização solidária. In: ॥ Corredor das Idéias, 1999, São Leopoldo, 1999. Acesso em março de 2008: <http://www.agoravirtual.net/mostra/corredor/velasco.htm>

. Ética para o século XXI: rumo ao ecomunitarismo. São Leopoldo: Ed. Unisinos, 2003. Introdução a Educação Ambiental ecomunitarista. Rio

Grande,

Ed. FURG, 2008.

VESENTINI, J. W. Realidade e perspectiva do ensino de Geografia no Brasil. In: O ensino de Geografia no século XXI. Campinas: Papirus, 2004. 